\title{
Hollowing the Infrastructure: Revolving Loan Programs and Network Dynamics in the American States
}

\author{
Laurence J. O'Toole Jr. \\ University of Georgia
}

\begin{abstract}
*Prepared for symposium on "The Hollow State: Capacity. Control and Performance in Interorganizational Settings," for the Joumal of Public Administration Research and Theory, 1995.

Part of this research was conducted in a study of SRFs supported by the U.S. Geological Survey through award 14-08001-G1746. John Heilman and Gerald Johnson were the principal investigators. The draft final report (Heilman and Johnson 1991), to which this author also contributed, contains additional information on initial state efforts, and an early explication of the perrpective and some of the themes explored bere. More recent research related to this project is reported in Morris (1994). The author is grateful for the support provided by the Geological Survey, and for the comments of these colleagues on an earlier version of this article. William Douglas Ballard provided research assistance for this article. Thanks are due to the University of Georgia, which supported additional field work for interviews and data gathering with EPA and sate infrastructure financing officials during 1994. Mention of these institutions and individuals does not imply their endorsement of the views and interpretations expressed herein.
\end{abstract}

J-PART 6(1996):2:225-242

\begin{abstract}
Trends toward more complex intergovernmental programs and greater use of public-private arrangements carry implications for public management, since these developments signify challenges for administrators called upon to manage within hollowed institutional settings: interorganizational networks for effectuating policy. The implications of such shifts are explored by examining one important program change of the last decade: the move away from federal grant support for municipal wastewater treatment infrastructure and toward the creation of separate state revolvingloan funds (SRFs). National regulatory standards remain, but the central place of the EPA in the infrastructure effort has shifted largely into other hands, with consequences for the implementation of policy. Altered policy instruments stimulate the formation of more complex network patterns involving new actors who offer needed technologies. These changes carry implications for program operations and results. Evidence from the operation of SRFs suggests that these developments are significant and also that public management has become, if anything, even more consequential in such networked contexts.
\end{abstract}

Since the late 1970s, a series of significant shifts has altered the context of public program management in the United States. National assistance for state and local efforts has decreased overall, despite exceptions. Beyond the simple fact of lean times, these changes signal management trials facing administrators at all levels of government. Policy agendas continue to grow, and the facts of administrative and programmatic interdependence are not erased simply by reductions in federal support. A strong case can be made that states, especially, have seen a resurgence in policy and administrative challenges and efforts in recent years (Beam 1993; Rivlin 1992). However, those who might interpret

225/Joumal of Public Administration Research and Theory 
these changes as a straightforward move to an era of dual federalism redux would be mistaken.

Instead of simplifying public management by placing the control of programs closer to the scene of the practical action, these shifts have contributed to an intricate process of complexification, the consequences of which only gradually are becoming visible. What is clear is that the modifications in the governmental patterns carry substantial implications in a number of policy sectors.

In some fields, in fact, national cutbacks combined with federal regulations have stimulated complicated networking dynamics, as states or local governments seek to address practical issues by tapping the skills, information, institutional capacities, and financial resources of other organizations to extend their reach in an era of public sector limitations. In a parallel development, governmental efforts to privatize the provision of goods and services have led to a more labrynthine structuring of relationships. Program managers are required to manage or at least influence clusters of private units toward approved policy objectives but are not able to control or fully regulate their behavior.

Both of these dynamics, toward more complexly networked intergovernmental programs and intricately patterned publicprivate ties, have been a product of recent efforts to simplify public responsibilities and limit government's role. Each also carries implications for public management, since each implies a set of challenges for administrators called upon to manage within the interorganizational networks that must constitute the arrays through which policy can be effectuated. In fact, as the evidence presented in this article suggests, the two trends are not simply parallel developments-they are linked. The shift of responsibilities to the states provides opportunity and incentives for increased involvement of ostensibly private actors in the management of public decisions. How public administration copes with these interdependent shifts carries ramifications for the capacity, control, and performance of public programs.

In this article, I explore this broad point by examining one intergovernmental shift developed within the last decade: the move away from federal grant support for wastewater treatment infrastructure and toward the creation of separate state revolvingloan funds (SRFs). The shift toward SRFs has been a consequential change in national and intergovernmental policy, even if this transformation has gone almost unnoticed in the research community (for exceptions see Heilman and Johnson 1991; Morris 1994). The now defunct construction grants program was one of 


\section{Symposium on the Hollow State}

the largest intergovernmental aid packages in history. As the state has been hollowed, SRF has begun to illustrate the issues implied by these changes.

The withdrawal of a generous federal grant program and its replacement by the capitalization of state revolving-loan funds has triggered alterations in the intergovernmental networks operating in this field. The shift can be understood, in part, in terms of a reduction of the role of the U.S. Environmental Protection Agency (EPA), the national unit long prominent in this, the most expensive segment of U.S. clean water policy. National regulatory standards remain in force, but the central place of the EPA in the infrastructure effort has largely shifted into other hands-with repercussions for the implementation of policy. While great variety characterizes the state-level arrays, the dynamics of the last few years have resulted in complex constellations of interdependent actors-altered networks-surrounding many of the evolving state-level programs.

From one perspective, then, the national state has become more hollow, as the central role in directing the states' responses to local needs has diminished. From a more comprehensive view, however, what has happened is more complex. National authority remains prominent: the stick is present, even if at some remove, but the carrot has shrunk and has been passed, baton like, into the hands of others. One policy instrument has been exchanged for another set, and with this move comes a hollowing of one portion of the nation's role.

The public administrative responsibility remains. Indeed, the modifications propel greater challenges for administrators. With few exceptions, the network constellations involved in policy implementation are now more complex in membership than they were previously; administrators continue to face program obligations but find themselves operating in network environments that are not so easily managed. Program demands, with foci on clean water goals and infrastructure development, remain in force. The more complex setting introduces the possibility that additional actors may play significant roles in policy. In such a setting, how can policy be implemented successfully? By cooperating with a diverse array of players although their goals and interests are somewhat at odds? By achieving progress toward public policy while the more networked context poses challenges on such central values as equity, accountability, access, and the public interest? These administrative issues are raised by this development. The questions are especially timely because at present this initiative is being considered in other substantive fields. 


\section{Symposium on the Hollow State}

In this article I explore these issues via SRF. I first outline the program shifts and then I examine complex and networked public programs like SRF via approaches based in institutional analysis by outlining one such perspective and using it to characterize SRFs. I then focus on one dimension of program variation across the states, explain how state choices on this issue influence the composition and structure of interorganizational networks surrounding SRF decision making, and examine a hypothesis regarding the consequent impact on program results. In the final section, I consider implications for public management.

\section{HOLLOWING AS PASSING THE BATON: THE CREATION OF SRFS}

The Clean Water Act and its amendments obligate the United States to control the release of waste into the nation's waters. Some pollutants, nonpoint sources like agricultural runoff, are not traceable to a particular discharge spot and entail complex control issues. Others, including industrial waste streams and discharge from wastewater treatment plants, long have been a focus of national policy. Most wastewater treatment is handled as a local government responsibility, with regulatory standards set by national and state governments.

Throughout the period of federal involvement, the policy instrument for point-source water pollution control has been a system requiring all such polluters to obtain a permit specifying precise emissions allowances. Monitoring and enforcement are handled through the EPA or state-level environmental agencies (SEAs).

Municipal wastewater discharges, subject to the permitting system, also have been addressed through a federal grant program to assist in treatment plant construction. The program grew to very large size (annual federal expenditures more than $\$ 5$ billion by 1980) and contained generous matching and eligibility provisions. As a result, there was improvement in the quality of discharges and much construction. Despite the program's popularity among state and local officials, critics claimed that some plants were overbuilt, states used federal monies to substitute for rather than to supplement their own, and the program had become too costly. Long delays in construction, caused by waiting lists of eligible projects and oversight exercised by EPA and SEAs, resulted in escalating overall costs.

In 1987, budget-cutting pressures at the national level and the Reagan administration's new federalism initiative contributed to significant changes in wastewater infrastructure financing 


\section{Symposium on the Hollow State}

policy in a revised Clean Water Act. The new law stipulated a gradual phaseout of construction grants and initial federal capitalization (with a modest state matching requirement) for new state-run revolving-loan fund programs throughout the country. The states were to have substantial discretion in running their own efforts at local assistance; such basic questions as determining priorities among local applicants, deciding whether and how to subsidize loan rates, and overseeing local project development were left up to the states. The wastewater infrastructure baton was passed to the states, but federal environmental regulations remained in force through a hollower EPA and its counterpart state agencies.

Federal contributions to SRF capitalization and to the construction grants phaseout were set at $\$ 18$ billion in toto through fiscal year 1994. (A one-year extension was approved for 1995.) Despite support from the states, further national funding for SRF is currently in question. Following capitalization, the states will be on their own for the financing task.

Once capitalization began, the states were able to operate their new SRF programs with substantial independence on a wide range of issues. Federal policy intends for repayments to replenish the funds, thus allowing the programs to continue in perpetuity. Some states supplemented their SRFs with either state-based grant programs or with an overmatch of funds into the program. However, in most states SRF constitutes the main option beyond local self-financing, an expensive proposition for many communities. All states and Puerto Rico now operate SRF programs; managers in these governments are engaged in myriad tasks of managing state funds, determining eligibility and priority for assistance, assessing the creditworthiness of potential recipients, negotiating and awarding loans, monitoring construction progress, and overseeing repayments from local governments.

Indeed, beyond a shift in policy instruments and funding, the move to SRFs has involved a change in administrative locus-and focus-for wastewater infrastructure development. The shift implies not merely a transfer from one level of government to another and not just an adjustment in types of administrative units involved. Significant alterations also have been made in the composition of the interorganizational networks operating in the sector. These network changes, furthermore, have brought modifications in program implementation and in the challenges facing public managers. 


\section{SRF PROGRAMS AS INSTITUTIONS}

Government programs entail policy instruments, criteria for action, and participants (including managers). By homogenizing or neglecting these different dimensions, analyses of regulation, privatization, grants, and loans can fail to clarify sufficiently the implications of complex program designs.

Three developments render the general terminology even more problematic. First, as some recent analysts recognize, many programs do not fit neatly into the traditional categories (see Kettl 1988; Salamon with Lund 1989). Second, governmental efforts may involve or encompass combinations of these types. The national government's strategy for addressing the municipal wastewater challenge during most of the last few decades, for instance, utilized both the carrot of federal grants and the stick of regulation to induce action. Neither is understood without clear recognition of its complement. Third, many governmental programs now include newer types of participants. Of particular interest is the involvement in public programs of businesses and not-for-profit organizations in numerous policy sectors. Such units can heavily influence policy and program design, management, review, and evaluation (see Kettl 1993). This point suggests the need for careful attention to the full networks of actors involved in public programs.

This implication bears on the analysis of SRF. The remainder of this article is structured to explore the connection between program features and networks, on the one hand, and public management issues and program results, on the other.

\section{AN APPROACH TO INSTTTUTIONAL ANALYSIS}

SRFs are loan programs. However, in the interest of pursuing greater conceptual clarity, it is useful to move beyond general labels and examine more detailed dimensions. Doing so can enhance understanding and permit exploration of more subtle differences among programs of generally similar design. For these reasons this treatment relies on an approach to institutional characterization developed by Elinor Ostrom and associates (see, for instance, Ostrom 1986).

Ostrom conceives of institutions as sets of rules that constrain and direct social action. The rules are not necessarily formal items, but shared understandings among relevant actors who may or may not be housed in the same formal organization. This conceptualization of institutions when applied to public programs can be helpful for exploring networked action, particularly 
since it directs attention to actual understandings and empirical patterns of interdependence rather than merely hierarchical arrays.

This form of institutional analysis emphasizes the variety and complexity of possible patternings by outlining the kinds of rules that, taken together, define any institution. Ostrom's set of rule types, employed here, is meant to provide complete characterizations for complex arrangements. The institutionally defining rules include boundary (specifying who is allowed in the action arena); position (setting positions, assigning actors to them, and stipulating tenure); authority (commissioning positions with legitimate actions); scope (indicating the features of context to be affected by actors' moves); information (determining who can control what data and its transmission); payoff (establishing benefits, costs, and their distribution); and aggregation (determining how collective decisions are fashioned).

Institutions are defined by these rule sets. Differences in institutional performance are explained by differences on one or more of these fine-grained dimensions. It is possible to treat SRFs as institutional arrangements amenable to comparison. Yet the huge number of institutional possibilities implied by this scheme poses a formidable barrier to theoretical development and empirical testing. Some scholars have suggested the wisdom of using a comprehensive approach to institutional characterization like Ostrom's but applying it in a strategically simplified fashion by testing propositions related to only one or two rule clusters at a time (Scharpf 1989).

This method is employed here. SRFs first are characterized in terms of program rules, and then the implications of certain choices regarding payoff and aggregation are explored. It is found that a choice for certain rules during state program design influences the overall character of the program-including network composition-and may carry, in turn, implications for both program management and policy results. The article concludes with some lessons regarding program management in such interorganizational settings.

\section{SRF INSTITUTIONAL FEATURES}

SRFs can be characterized briefly in the terms outlined earlier:

Boundary, position, and authority rules. SRFs set up states as the decision makers on wastewater infrastructure financing, and within states substantial discretion is left to the governments 
themselves to select-or design-one or more administrative units as centers of program decision making. Local units of government have roles as potential loan recipients, entering via competition among those wishing assistance. EPA and state regulators recede from their roles as line managers under the earlier grants program. Beyond these formal actors, and depending on the rule choices made by states regarding payoffs, additional participants may be noteworthy. The most important are organizations in the banking and finance industry. Their involvement is virtually required when states elect certain approaches (see below). Under such circumstances state agencies remain authorized as the decision centers, but influence can shift significantly toward market actors and their agents. In short, program rules in many states influence the composition of the relevant interorganizational networks, granting new participants-sometimes including both public and private units-substantial roles in SRF operations.

Scope and information rules. State decision makers are allowed great scope in the design and operation of their programs, and all evidence indicates the range of variation across the existing programs is considerable. Some federal rules and reporting requirements must be met, and certain crosscutting national regulations have narrowed institutional scope at the state level on some matters. The most important realm of scope has to do with range of allowable payoff rules (see below). As public programs, SRFs must allow fairly widespread access to programrelated information, and, given the importance of regular repayments to maintain program solvency, SRFs typically require large amounts of financial information from potential loan recipients. These requirements, designed to assess creditworthiness and, in some cases, financial need, also constitute a significant change from the earlier grants program. Although the level of information available is considerable, EPA and national environmental decision makers have performed little policy analysis. One outside national agency, the General Accounting Office, has done some empirical research and pointed to selected implications of financing choices (see GAO 1992).

Payoff and aggregation rules. States have great discretion in determining program beneficiaries (via priority rules and discretion in individual selections), levels of benefit (loan awards, interest rate subsidization), and repayment schedules. The variation across the states is suggested by the fact that loan interest rates currently range from near-market levels down to negative rates (rates that do not preserve principal, even assuming perfect repayment and zero cost of capital). The realm of choice is wide; in fact, states are permitted to fund certain projects excluded from consideration by the grants program (estuary protection, 
some control of nompoint source pollution), although almost all of the aid has gone for traditional wastewater projects. And, of particular significance, the form and amount of financing is also an issue left entirely to state discretion. Aggregation rules vary from state to state as well; in some instances SEAs make state choices, in other instances finance agencies make the choices. Some states require interunit concerted choice, others place political actors in position to aggregate or even ignore recommendations from the bureaucracy.

Clearly, no simple shorthand (like loan program) captures either the important working parts of SRF or the sense of variation possible under federal policy. Fifty-one quite different institutions have been established (see Heilman and Johnson 1991 for a review of early evidence on the programs' structures and performance).

It is impossible to provide here a comprehensive analysis of all these institutional features and their consequences for management and policy. Instead, one payoff rule, or cluster of rules, is selected for particular attention in the remainder of this article. The evidence suggests that state choice on this set of issues has three important consequences: It helps to determine other rules defining the SRF institutional arrangement; it compels managerial dependence on certain technologies and forms of expertise; thus drawing particular kinds of actors into key roles within the interorganizational program structure; and it influences program results.

\section{THE LEVERAGING DECISION}

An especially important set of rules available for adoption in state SRFs has to do with the choice regarding financial leveraging. One infrastructure financing expert gives a succinct summary of the general issue:

Leveraging in the SRF context means that states have discretion to use the federal capital grants, as well as their matching share, as collateral to borrow in the public bond market for purposes of increasing the pool of available funds for project lending. This option, specifically provided in Title VI of the Clean Water Act amendments of 1987, allows the states to use the funds as security or a source of revenue for the payment of principal and interest on bonds, so long as the bond proceeds are deposited back into the SRF. Security for the bonds may be provided by any of the SRF assets including anticipated future revenues from loan repayments. (Ladd 1994, 1)

Primarily because leveraging multiplies the size of the loan pool, it is a choice viewed favorably among state infrastructure financing specialists. Nearly $\$ 4$ billion of additional funds already 
have been added to state loan pools through this approach. For present purposes, the leveraging choice for states can be considered binary (either to leverage or not), although finance specialists appropriately would point out that several leveraging structures are possible (for examples of principal alternatives now in use, see Ladd 1994, 4-12). As of the end of 1994, eighteen states had adopted SRF leveraging.

Many implications of leveraging lie beyond the scope of this analysis. Here the focus remains on the threefold set of ramifications identified above.

- Leveraging influences other rules by which SRF institutions operate. The choice to leverage offers attractions, particularly because of obvious payoff impacts: A relatively small federal capitalization can go an especially long way. In cases where local demand for infrastructure loans is high, leveraging provides a responsive approach rather than one reliant on inevitably slow repayment streams.

Additional influences on the rules of the SRF game are less obvious. Indeed, some were not foreseen by policy makers and program managers at the outset of program design. One instance is the determination that, while leveraging increases the size of the loan pool in the first years, it lowers capital available later unless states decide to supplement the program with substantial amounts of their own monies later (see GAO 1992; Holcombe 1992). Charging higher rates for loans also can help to mitigate the erosion of a state's SRF corpus. The full payoff implications of the leveraging arrangement are complex, as subsequent analyses have demonstrated. Partly as a consequence, certain states that might benefit from leveraging arrangements have avoided the option.

The implications of leveraging for SRF institutions do not stop here, however; the leveraging decision also carries networking implications.

- Leveraging influences SRF program technologies and helps to determine needed expertise; thus, it carries consequences for program networks and management. Operating a leveraged SRF program means that state managers need substantial expertise in banking and finance, technologies traditionally not available in either SEAs or the organizations in their proximate environments. Even for states that choose simpler loan program structures, SEAs were often not prepared to manage SRF operations: performing credit checks, overseeing repayments, or marketing loans to municipalities. 


\section{Symposium on the Hollow State}

SEA units involved in the construction grants program typically had been staffed and often had been managed by engineers who, rather than devoting time to complex financial management, had devoted considerable attention to overseeing construction activities and complying with environmental standards. Aside from EPA, the program network basically had consisted of portions of the SEA, perhaps an association of local governments, and individual municipalities. Therefore, even in some of the states opting for "plain vanilla" SRFs, an infusion of financial expertise into program management typically was needed. Such states often continued to house prime responsibility for their program in the SEA but linked one or more state financing agencies to the program structure, thus increasing the interorganizational network. In such instances, the SEA might continue to set priorities, in terms of the kinds of criteria used to select candidates for loans. However, the other unit(s) might be charged with handling components such as determining credit worthiness or analyzing loan options for local government officials. SEAs lost some degree of program influence in many states, in certain cases reluctantly.

More significant changes have been triggered in states that have chosen leveraging. Management of a sophisticated financing operation-often involving complex techniques used by traders and analysts in today's bond markets-involves considerably more resources and knowledge of banking and finance. SEAs have been unfamiliar with such issues, thus states considering leveraging usually have moved their wastewater programs into a finance unit; established a new organization (such as an independent financing authority) to manage operations; or combined these approaches with the use of outside expertise, including bond counsels, financial consulting firms, and investment banking organizations. Indeed, since leveraging means selling bonds in the market, this program structure inevitably involves market actors and intermediaries in merchandising loan portfolios to investors-typically institutional investors. States deciding to leverage, then, typically have been inclined to alter formal administrative arrangements for their programs. They also have found that programs require an altered interorganizational context during operation; in many such states, organizations that specialize in finance and the market have become influential.

In interviews, for instance, environmental managers in several states indicate a lack of knowledge of their own financial program structure and its operations. (State finance officials, on the other hand, tend to see and understand SRF as an infrastructure investment program and to see this arrangement as advantageous: more and faster construction, more efficient design, and 
reduced regulation.) In leveraged states SEAs quite often have ceded decision making on several payoff issues to the newer entrants in the network.

These changes have had additional impacts in the network of actors surrounding the official structure for program management, as well as in the criteria used for loan decisions. Leveraging connects state programs directly and necessarily with the bond market-including its core actors with their special focus and concerns. Using federal funds to borrow more, in the interests of rapid infrastructure development, means moving criteria of financial soundness-and those who render professional judgments about such issles-to important places in program decision making. The inclination of financial actors is to focus on sound financial condition and to rely on the approval and perspectives of bond rating agencies and investment bankers.

In a leveraged state, then, the program network typically might consist of a state environmental unit; one or more finance units; an advisory group consisting of representatives of financial firms; and representatives of other state agencies and local governments. In addition, the program network might have contractual relations with bond counsel, investment bankers, and perhaps a private financial consultant.

One state provides an extreme instance of the influence of the new private entrants in a leveraged program setting. In this case, a private finance firm advising state program managers claims to set state priorities for a portion of the loan pool by moving certain communities onto-or off-the aid list on the basis of the firm's private judgment of local financial conditions. Here, when environmental and financing criteria point in different directions, the private advisory unit makes choices without public discussion of the tradeoffs or their implications. In other states, the environmental-finance tension is handled differently, either by having public program managers make the decisions more explicitly and thus more accountably or by seeking to create separate channels-or another program-to handle the inevitable cases of communities with pressing infrastructure needs but insufficient local resources to constinute a good credit risk. Regardless of the approach, leveraged states operate programs in which the leveraging instrument has drawn important new actors and organizations into decision making. The assistance choices made as a consequence are often different than they were before SRF.

In SRF programs structured to leverage, and with a portion of the network focused primarily on finance and investment, 


\section{Symposium on the Hollow State}

infrastructure development can become a very different kind of program than that prevailing heretofore, when the emphasis was on subsidizing local wastewater efforts and overseeing the engineering and water quality details. Programs premised on the sale of bonds must develop a portfolio that is attractive to investors-and thus to investment bankers and bond specialists on Wall Street. States are dependent on sales to investors; state program managers, typically via the financial advisers and firms in the network, sell bonds on the basis of potential for income rather than environmental improvement. These network shifts can alter the character of program operations and management; they also can affect program results.

- The choice to leverage and the consequent shifts in program and network structure influence program operations and program results. Interview evidence suggests that states choosing leveraged arrangements tend to focus more on financial mechanisms and specialists generally and to engage in less regulatory oversight of infrastructure design and construction. State loan data analyzed below support the proposition that they also tend to emphasize different kinds of loan recipients in decisions regarding state aid. As I have suggested above, this latter tendency is encouraged by the new network participants induced, and even required, by the leveraging decision. The latter point regarding the results of program management suggests the importance of both program design and interorganizational network composition for policy results.

An expectation implied by the foregoing analysis is that, ceteribus paribus, the network context of program management for leveraged state programs can be expected to encourage distribution of aid toward communities that are seen as attractive investments, at the expense of those viewed as financially risky or those that are very small. The latter group often lack credit ratings, face barriers to the bond market, and have limited tax bases and financial management capacity. The special needs of small communities, therefore, have been a focus of policy analysts in this field.

What does the evidence from the states show? No data set available from the states or EPA has information sufficiently precise and reliable to address directly the question regarding financially risky communities. Analyzing this issue would require surveying the states directly (see Morris 1994). Information is available, however, regarding the relative treatment of small communities (those with fewer than three thousand inhabitants) in different types of state programs. These data are reported on an annual basis (see Grossman 1994). Examining the treatment of 
small communities can provide a sense of the consequences of SRF for jurisdictions that are less attractive to market-oriented actors.

The hypothesis suggested by the foregoing analysis is that leveraged state programs give a relatively smaller proportion of state aid to small communities than do other programs that do not leverage and therefore do not rely as often or as directly on market-based actors. How have the nation's small communities fared through SRF? More precisely, do leveraged programs and their more market-focused networks treat these units differently than do programs in other states? Two findings are of particular interest.

First, leveraged programs distribute a substantially smaller portion of their loan assistance to small communities than do nonleveraged programs (see exhibit). As a group, the latter provide more than 17 percent of total SRF dollars to their smallest locales, whereas leveraged programs have distributed a smaller portion (of their larger pool) to locales under three thousand: less than 5 percent in 1994 (Grossman 1994). The hypothesis regarding the impact of program design and network composition on results is supported.

\section{Exhibit}

SRF Loans to Small Communities, 1994 (as percent of loan dollars)

\begin{tabular}{lcc}
\hline & Leveraged & Nonleveraged \\
\hline Total dollar volume, nationwide & 4.91 & 17.16 \\
& 7.88 & 15.52 \\
Mean state level & & $47.83(49.05-1.12)$ \\
Range among states & $24.76(25.04-0.28)$ & 11.29 \\
Standard deviation across states & 7.92 & 49 \\
*Number of states included is 38, the total reported in Grossman (1994).
\end{tabular}

This difference has not resulted in leveraged states having an advantage in terms of loan repayments. Several years into SRFs, no locales in any states have defaulted. But the distribution of aid apparently has favored relatively safer recipients in the states tied more closely to the market via leveraging and the networks of associated participants. This is not to say that leveraged states cannot deal with small and/or financially distressed communities 


\section{Symposium on the Hollow State}

via an additional state-initiated program or a set-aside of funds for these kinds of localities. Several states have acted on their own to do just that. But market-based SRFs as a group do seem to be less responsive to the nation's small jurisdictions.

Second, and of considerable importance for those interested in public management in networks, is the finding that despite the difference in impact between these two groups of programs, only a relatively small portion of the variance across states in program decisions is explained by the leveraging structure. (With state programs as units of analysis, standard deviations for the two program types are approximately 8 and 11 percent of loans, respectively; see exhibit.) Leveraging and leveraging networks clearly matter for program results. But within each program type a great range can be found. Among states that opt for leveraging are some that direct considerable resources to small communities and others that do not; it is the same in states that choose not to leverage. To some degree these differences are products of legislation that is aimed at setting priorities and of demographic and demand characteristics in the states. However, evidence available from discussions with state managers and national officials suggests the range of these differences is also a result of conscious strategies adopted by program managers in the states and exhibited in different approaches to program marketing and implementation as well as the general exercise of discretion in program networks.

\section{PUBLIC MANAGEMENT IN INTERORGANIZATIONAL NETWORKS: SOME LESSONS FROM SRF}

The SRFs can offer lessons carrying import far beyond wastewater. Pressures on the national budget seldom have been more intense, and this form of program shift-from costly grants to the establishment of state-run loan efforts-is therefore being contemplated across a range of capital-intensive policy issues from drinking water to transportation infrastructure. Even more generally, the SRF experience can prove instructive as hollowed governments experiment with complex program structures involving more organizational actors, interorganizational networks, and public-private links.

The SRF instance suggests that decisions to shift programs to the states, deregulate, privatize, and employ marketbased mechanisms have consequences for both interorganizational arrangements and programs in practice. These implications are not captured by the rhetoric of political debate, nor are they explained very well by general notions used by specialists in policy and program management. More elaborate, less 
conceptually loose approaches are probably necessary to understand how today's structurally more complex programs are likely to work.

The SRF experience also suggests some lessons of special relevance to those interested in interorganizational networks, market-oriented approaches to policy, and the role of public management.

Policy innovations contain interorganizational implications. Program design choices influence the institutional arrangements within which policy-relevant action develops, including the clusters of interdependent organizational actors that congeal around implementation action. A move from construction grants for wastewater treatment to SRF not only places the states on the front lines of the infrastructure battle, it brings banking and finance units, public and private, much more directly into decision making. EPA and SEAs, in turn, have receded in involvement and influence. These generalizations are especially true in those states that have opted for program instruments like leverag ing that require the active efforts of finance units in basic features of state decision making.

A shift toward programs and interorganizational structures focused on the market carries consequences: more rapid deployment of infrastructure resources, more incentives for efficient performance, and more focus on financial soundness. At the same time, there is less focus on regulatory oversight and the needs of financially distressed communities with environmental needs. Some of these program effects were anticipated nationally and in the states at the time of program design; others were byproducts of the emphasis on the market and its institutions and on the preferences, technologies, and requirements of those institutions.

Program design and network composition matter, but they do not straightforwardly determine results. What is equally clear is that public management becomes, if anything, even more consequential in program arrangements such as SRFs. The placement of programs into administrative units (for instance environmental vs. financial) affects the choices that are made. State managers have impact, even among programs of common type-leveraged or nonleveraged-and those that involve many similar organizational units in program operations. The influence can come directly, in the way state officials make program decisions, or the effects can be mediated by managers' efforts to shift the network composition within which they operate-encouraging the involvement of additional organizations, marketing the program toward 
selected customers, or subtly involving certain political actors in program oversight.

Finally, such conclusions carry further implications for the public management challenge in interorganizational settings. More complex networked contexts like those surrounding SRF are not easily controlled by those who operate public programs. Intergovernmental ties, and increasingly horizontal interagency and public-private links, are not subject to unilateral, authoritative supervision by those charged with program responsibilities. More open and especially more market-oriented networks offer prospects for certain kinds of efficiencies. The weakening of grant-supported chains of picket-fence federalism provides opportunities for additional and perhaps more broadly representative interests to become involved in patterns of decision.

Without substantial management capacity, appropriate oversight mechanisms, and conscious and informed choice by program decision makers, the potential for error is real, however. In the SRF instance, environmental goals might be unwittingly and unnecessarily compromised for financial goals, suboptimal distributions of assistance might emerge as a by-product of altered program networks, and private actors and interests might exert inappropriately strong and unaccountable influence in public programs-as has occurred in some states. The SRF evidence suggests that these consequences are not inevitable, that in fact the program's design at the national level allows for a huge range of choice among the states, and that this potential for choice is being exercised. Program management in this niche of the hollow state holds the potential to balance the perspectives of the actors involved in infrastructure development, from the Main Streets of local communities to Wall Street and from environmental regulators to giant infrastructure development companies. But such a result is far from automatic. The evidence indicates that in networks for infrastructure, responsible and capable public mánagement is complex, interorganizational, and consequential.

Beam, David R.

1993 "Reinventing Federalism: StareLocal Government Roles in the New Economic Order." In Laurence J. O'Toole Jr. American Intergovermmental Relations, $2 \mathrm{~d}$ ed. Washington, D.C.: CQ Press, 378-91.

\section{REFERENCES}

GAO (U.S. Genenl Accounting Office).

1992 State Revolving Funds Insufficient to Meet Wastewater Treatmens Needs. Report to the chaiman, Committee on Public Works and Transportation. House of Representatives.
GAO/RCED-92-35. Washington, D.C., Jan.

Grossman, Steven.

1994 "1994 Annual SRF Survey." Ohio Water Development Authority (processed), Nov. 14 draft. 
Heilman, John G., and

Johnson, Gerald W.

1991 State Revolving Loan Funds: Anatysis of Institutional Arrangements and Distributive Conseguences. Draft report for the U.S. Geological Survey, Department of the Interior, Award No. 14-08-001-G1746.

Holcombe, Randall G.

1992 'Revolving Fund Finance: The Case of Wastewater Treatment." Public Budgeting and Finance 12:3:50-65.

Kettl, Donald F.

1988 Government by Proxy: (Mis?) Managing Federal Programs. Washington, D.C.: CQ Press.

1993. Sharing Power: Public Governance and Private Markets. Washington, D.C.: Brookings.
Ladd, Paul.

1994 . Leveraged SRF Programs: A Comparative Review. CIFA monograph no. 6 . Washington, D.C.: Council of Infrastructure Financing Authorities, Aug.

Morris, John C.

1994 "Privatization and Environmental Policy: An Examination of the Distributive Consequences of Private Sector Activity in Strte Revolving Funds." Ph.D. diss., Aubum Uriversity.

Ostrom, Elinor.

1986 "A Method of Institutional Analysis." In Franz-Xaver Kaufmann, Giandomenico Majone, and Vincent Ostrom, eds. Guidance, Control, and Evaluation in the Public Sector. Berlin: de Gruyter, 459-75.
Rivlin, Alice.

1992 Reviving the American Dream. Washington, D.C.: Brookings.

Sulamon, Lester M., ed. with the assistance of Michael S. Lund.

1989 Beyand Privatization: The Tools of Government Action. Washington, D.C.: Urban Institute.

Scharpf, Fritz W.

1989 "Decision Rules, Decision Styles, and Policy Choices." Joumal of Theoretical Politics 1:2:149-76. 